\title{
Respiratory diseases in the world: one voice "united for lung health"
}

\author{
Peter J. Barnes ${ }^{1}$, Francesco Blasi ${ }^{2}$, Brian Ward ${ }^{3}$, Elin Reeves ${ }^{4}$ and Klaus F. Rabe ${ }^{5}$ \\ Affiliations: 'National Heart and Lung Institute, Imperial College, London, and ${ }^{4}$ European Respiratory Society, \\ Publications Office, Sheffield, UK. ${ }^{2}$ Dipartimento Fisiopatologia Medico-Chirurgica e dei Trapianti, University \\ of Milan, IRCCS Fondazione Cà Granda, Milan, Italy. ${ }^{3}$ European Respiratory Society, European Affairs \\ Dept, Brussels, Belgium. ${ }^{5}$ Zentrum für Pneumologie und Thoraxchirurgie, Krankenhaus Großhansdorf, \\ Großhansdorf, Germany.
}

Correspondence: K.F. Rabe, Zentrum für Pneumologie und Thoraxchirurgie, Krankenhaus Großhansdorf, Großhansdorf, Germany. E-mail: k.f.rabedlungenclinic.de

0

@ERSpublications

Ten essential actions recommended by the Forum of International Respiratory Societies: "united for lung health" http://ow.ly/r3qdQ

The lungs are essential organs for life. However, lung diseases (including at least 10 major conditions and many more rare and orphan diseases) cause pain and suffering for millions and are among the leading causes of mortality worldwide. There are many risk factors for respiratory disease, which can start from a very early age, although many are avoidable and their effects treatable.

As a society, over the years, the European Respiratory Society (ERS) has been quick to respond to changing health priorities, and to raise awareness of respiratory medicine in the media and attract the attention of policy makers in Europe. In 2013, the society launched a new edition of The European Lung White Book [1], which draws on the latest data from the World Health Organization and European Centre for Disease Prevention and Control, and input from experts from around Europe to present a rigorous examination of the current state of lung health and disease, and an analysis of future trends.

Beyond Europe, the ERS is also a member of the Forum of International Respiratory Societies (FIRS), a partnership of international respiratory societies. Its member organisations also include the American Thoracic Society (ATS), American College of Chest Physicians (ACCP), Asian Pacific Society of Respirology (APSR), Asociacíon Latinoamericana de Tórax (ALAT), Pan African Thoracic Society (PATS) and the International Union Against Tuberculosis and Lung Disease (The Union), along with observer participants Global Initiative for Asthma (GINA) and Global Initiative for Chronic Obstructive Lung Disease (GOLD).

FIRS was set up in 2001 with the aim of highlighting the importance of respiratory disease for global health and prosperity. November 20, 2013 saw the launch of a collaborative effort of FIRS: a report entitled Respiratory Diseases in the World. Realities of Today-Opportunities for Tomorrow (fig. 1) [2]. In this report, the world's leading lung societies have come together, as one voice, to call for a worldwide effort to improve healthcare policies, systems and care delivery, to make a positive difference to the lung health of the world. While each component society seeks to improve respiratory health in their own continent and/or region, this collaboration is unique in that it harnesses and builds upon these efforts and brings them to a global arena.

The purpose of the report is to raise awareness among those who advocate for protecting and improving respiratory health. The report is intended as a guide to five respiratory diseases that account for the greatest burden to society in terms of morbidity and premature mortality: chronic obstructive pulmonary disease, asthma, acute respiratory infections, tuberculosis and lung cancer. It outlines the scope of each disease, methods for prevention, treatment, and long-term control or elimination.

Received: Nov 192013 | Accepted: Nov 192013

Conflict of interest: B. Ward and E. Reeves are employees of the European Respiratory Society.

Copyright @ERS 2014 


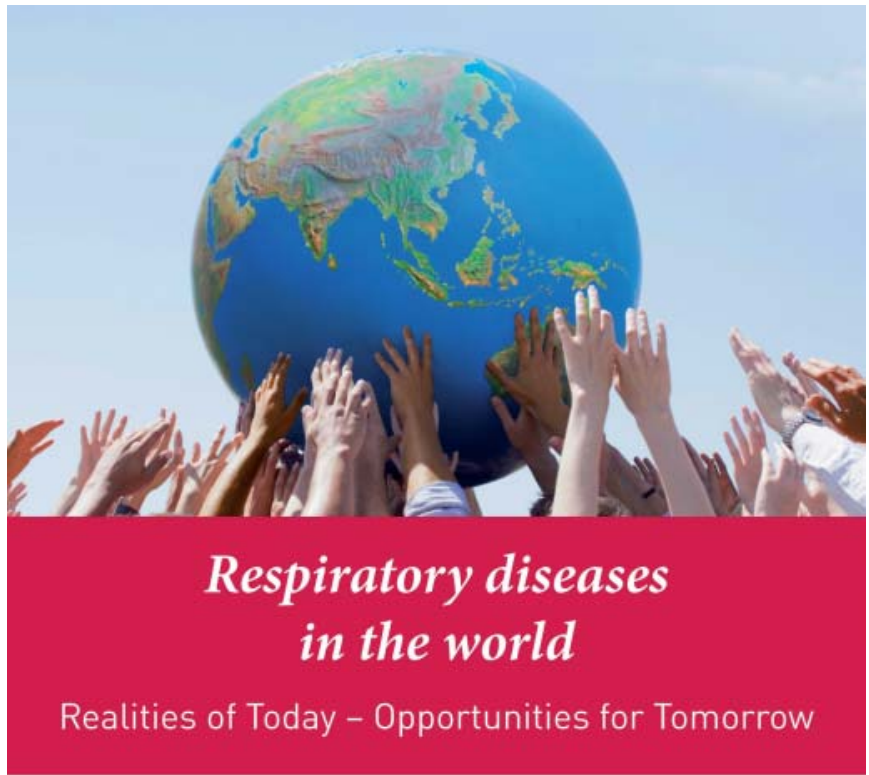

Forum of International Respiratory Societies

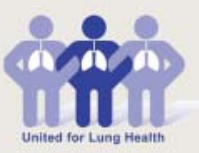

FIGURE 1 FIRS report: Respiratory Diseases in the World. Realities of Today - Opportunities for Tomorrow.

The report ends with 10 key recommendations (table 1), which are considered to be essential actions to reduce the burden of respiratory disease and improve global health. These recommendations are fully in line with ERS advocacy priorities and actions laid out on an annual basis and implemented through a public health presidential plan [3]. To help convey these messages, the ERS has organised annual summits since 2011 to set out the direction for respiratory medicine and research priorities over the long term [4].

In speaking with one voice, the ERS and other international societies will strengthen the weight of our messages to policy makers with regard to today's realities of respiratory health. Moreover, through publication of editorials in the societies' journals, FIRS hopes to reach out to as many respiratory

\section{TABLE 1 Essential actions to reduce the burden of respiratory disease}

\section{Recommendations}

Increase public and policy makers' awareness that respiratory health is essential to global health and for improving national economies Increase public and policy makers' awareness that childhood respiratory disease is a major cause of childhood illness and has long-term negative consequences on adult health

Urge policy makers to enable universal access to quality healthcare, including the availability of essential medications for all those with respiratory disease

Reduce and then eliminate the use of all tobacco products

Reduce ambient, indoor and occupational air pollution

Provide universal coverage for childhood and adult immunisations, including new conjugate vaccines

Improve early diagnosis of respiratory diseases

Recognise the impact of malnutrition, obesity and physical activity on respiratory conditions and implement plans to correct these concerns Increase education and training of health professionals in respiratory disease worldwide

Increase respiratory research to develop programmes, tools and strategies to better prevent and treat respiratory diseases

Reproduced from [2]. 
professionals as possible and to ensure these messages are heard and actioned. This is crucial to pave the way and ensure better opportunities for tomorrow.

\section{References}

Gibson GJ, Loddenkemper R, Sibille Y, et al., eds. The European Lung White Book. Respiratory Health and Disease in Europe. Sheffield, European Respiratory Society, 2013. Available from www.erswhitebook.org.

2 Forum of International Respiratory Societies. Respiratory Diseases in the World. Realities of Today - Opportunities for Tomorrow. Sheffield, European Respiratory Society, 2013. Available from www.ersnet.org/images/firs-world-report.pdf Blasi F, Barnes PJ, Gaga M, et al. Future directions for the ERS: Presidential plans. Eur Respir J 2013; 42: 875-880. Blasi F, Barry M, Ward B. Reaching the golden milestone. The 2013 ERS Dublin summit: preparing the road to Rome. Eur Respir J 2013; 42: 881-884. 